\title{
The Rise of the Modern Intelligence State
}

\author{
John Hardy
}

\begin{abstract}
The rise of the formal surveillance state in the early twenty-first century was precipitated by political impetus to empower security and intelligence organisations to perform a broad range of counterterrorism functions. Ethical debates about the implications of the security intelligence reach of modern states have focused on balancing individual rights, liberties, and privacy against the security of the state. Meanwhile, the surveillance state has rapidly evolved into an intelligence state, capable not only of pervasive data collection, but also of analytical modelling which expands existing boundaries of surveillance. Existing concerns about the ethical collection and use of surveillance data are compounded by three emergent capabilities of the modern intelligence state: persistent data surveillance, pattern-of-life analysis, and activity-based intelligence. These intelligence methods provide descriptive and/or predictive models of human behaviour that empower governments to generate intelligence about the actual and the potential subjects of counterterrorism investigations. The ethical implications of counterterrorism intelligence extend beyond the collection and use of data to the application of predictive modelling to dehumanised patterns of behaviour. This process has the potential to redefine the boundaries of the person, particularly by blurring the distinction between thoughts and actions which threaten the state.
\end{abstract}

\section{Introduction}

An international cohort of formal surveillance states emerged around the world during the early twenty-first century [84]. The group of countries that pursue national security through domestic surveillance and intelligence regimes grew throughout the 2000 s into a wide and varied cohort in the 2010s $[44,85]$. The political impetus to enhance national security from both internal and external threats was buttressed by the unprecedented availability and affordability of technology solutions to security

\footnotetext{
J. Hardy ( $\bowtie)$

Rabdan Academy, Abu Dhabi, UAE

e-mail: jhardy@ra.ac.ae

(C) The Author(s) 2021

A. Henschke et al. (eds.), Counter-Terrorism, Ethics and Technology, Advanced Sciences and Technologies for Security Applications, https://doi.org/10.1007/978-3-030-90221-6_7
} 
challenges. The security state quickly became a surveillance state and now armed with the resources and reach into the everyday lives of its citizens, the security apparatus of many countries was transformed from a sprawling bureaucracy into an omnipresent institution. This spurred debates into the role of the state in safeguarding the liberty and privacy of individuals while also protecting the people and their interests from harm $[47,87]$. While many of these debates remain unresolved, the rapid expansion of the state security apparatus, particularly in the advanced economies, has continued at increasing pace. Recent advancements in computer science and human understanding of analytical methods have empowered a modern intelligence state capable of deeper insight into the lives of individuals than the surveillance state that preceded it. Meanwhile, the post-9/11 political climate has enabled the rise of the intelligence state under the auspices of counterterrorism and national security [17].

The intelligence state combines the essential features of the security state and the surveillance state, protecting the homeland from internal and external threats through pervasive data collection and proactive policies aimed at counterterrorism and countering violent extremism [77]. It extends the reach of the security apparatus further by incorporating a broad range of analytical tools which enable analytical modelling and predictive analytics which stretch existing boundaries of surveillance [3]. Existing concerns about ethical conduct within mass surveillance programs are exacerbated by persistent data surveillance, pattern-of-life analysis, and activity-based intelligence. These analytical techniques provide both descriptive and predictive models of human behaviour that enable Governments unprecedented and invasive access to personal information for the purposes of enhancing counterterrorism. Routine encroachment of the intelligence state on the personal data of citizens has the potential to allow access to personal spaces by eroding the boundaries of privacy, to identify patterns of behaviour which fit risk profiles, and to create a system of control over access to information akin to Deleuze's [24] society of control.

The remainder of this chapter proceeds in three sections. The first section examines the gradual normalisation of mass surveillance as the state's technological omnipresence became a mechanism of discipline, security, and control. The second section examines the evolution of the surveillance state. It argues that the security state, which rose in tandem with Beck's [7] risk society, focusing more on technological solutions to domestic and international threats to homeland security than on traditional threats to national defence and security. The surveillance state rose in tandem with the evolution of big data. The generation, availability, and collection of an increasing number of data points from a rapidly expanding pool of sources led to the creation of modelling technologies that allowed states to build comprehensive profiles of citizens' patterns of life. The shift into an intelligence state has evolved alongside the fourth industrial revolution, utilising data surveillance, pattern analysis, machine learning, and predictive modelling to reduce the individual to a construct comprised of dividual data. The third section examines the "dividual' 1 in the intelligence state and the implications of systematic analysis of dividual lives include the reduction of human lives to data points, behavioural analysis, and predictive algorithms. It

1 'Dividual' is a term coined by Gilles Deleuze, see discussion below. 
argues that enhanced surveillance technologies routinely violate extant boundaries by giving the state access to previously non-observable thoughts and actions. This raises further questions about the rise of new technologies of control as innovations in Information and Communication Technologies (ICT) continue in the twenty-first century.

\section{The Normalisation of Surveillance}

Surveillance has been a function of the state in one form or another for much of recorded human history. The concept of an information state, which collected, processed, and stored information about its citizens has been popular among historians who generally link advances in technology as a defining characteristic of both modernity and the modernisation of the state [88]. The roles and functions of surveillance in the modern nation-state have served three key purposes. The first purpose was the ability to identify individuals in order to hold them accountable for aberrant or criminal behaviour in what Foucault [28] termed the disciplinary society. The second purpose was to manage the security and threat perceptions of individuals by promoting the state's ability to 'police' societies by deterring crime and deviance, to monitor society, and to prevent, mitigate, and respond effectively to major threats to security $[16,72]$. The third purpose was to establish a system of control by enabling the state to construct public places, information systems, and individual interactions such that it facilitates the exchange of information and access to systems of information exchange [24]. This "panvasive" system is both pervasive and invasive, eroding the boundaries between the public and private, and collecting data from individuals indiscriminately [79].

\subsection{Surveillance as Control}

Foucault [28] depicted the emergence of societies of discipline as a product of successive societal institutions enclosing individuals into systems of rules and norms where behaviour was monitored, and compliance was rewarded and enforced. One key distinction between the societies of sovereignty of the past and the disciplinary societies from the eighteenth century onward was the purpose of governance. Where societies of sovereignty governed to retain power, raise taxes, and adjudicate over death, disciplinary societies sought to organise and administer both the individual and the collective [28]. Despite the popular conception of Bentham's panopticon as a foundation for contemporary theories of surveillance [60, 82], the act of surveillance is only one aspect of panopticism in the disciplinary society. Foucault's panopticon was an apparatus not only of pervasive surveillance and data collection, but also an environment characterised by ubiquitous institutional power, which could exert the political influence of potential surveillance over individuals at any time [25]. In 
this conception, discipline is a mechanism of power that regulates the thoughts and behaviours of social actors through subtle means, increasing their docility and utility within society ([28], 231).

Deleuze [24] saw the disciplinary society as the foundation for a more comprehensive system of social compliance, once which was characterised not by surveillance and punishment, but by control. In a society of control, panopticism is not limited to the act of surveillance or the data being record. Rather, the panoptic system modulates social behaviour through access to information and opportunity ([25], 26). The metaphor of an omnipresent Big Brother perpetually watching society is less relevant to a society of control due to modes of participation in society which categorises and regulates the individual according to specified criteria which determine eligibility, inclusion, access, suspicion, and privilege ([49], 20). The society of control uses surveillance technologies to discriminate, assess, categorise, and profile individuals in what Gandy [30] has termed the "panoptic sort." Deleuzian control presents a surveillance state which sustains a self-governing machine that exercises the subtle coercion of Foucault's disciplinary society while constructing a societal landscape which moderates and modulates public places, information systems, and individual interactions. The society of control thereby facilitates both the exchange of information and individual access to collective systems of information exchange [25].

The society of control has been further enabled by advances in technology which fall into two categories. The first category is surveillance technologies which enhance the quality, volume, and integrity of collected data. The second category is analytical technologies which allow the state to construct new data from the products of its surveillance apparatus, to reduce risk, and to reduce the individual into a "bundle of data" to be collected, collated, and controlled ([23], 321). ${ }^{2}$ Through a process of "surveillant assemblage," the state is able to combine data is has collected and analysed about the individual and then generate an abstraction, or virtual identity, of that individual ([32], 608-610, [36], 11-12). Technological evolution throughout the early twenty-first century has changed the character, if not the nature, of the surveillance state with rapid advances in the means of controlling information and access. The trend toward mechanisms of control in the contemporary intelligence state has been supported by the increasing invisibility of surveillance in digital societies. This has been compounded by the growing acceptance of surveillance in the post-9/11 world and by the increasing complicity of individuals in subjecting themselves to data surveillance through consumer technologies [36, 63]. Increasing control and the normalisation of surveillance in many societies has brought the modern state to the precipice of existing ethical boundaries, sparking debates over the extent and appropriateness of mass surveillance programs justified under the auspices of counterterrorism and national security.

\footnotetext{
${ }^{2}$ Similar points were made by Daniel Solove in his 2004 The Digital Person, and by Adam Henschke in his 2017 Ethics In An Age Of Surveillance, where they talk about the use of surveillance technologies to create a 'digital person' or a 'virtual identity', respectively.
} 


\subsection{Ethical Boundaries of the Surveillance State}

The notion of privacy in relation to surveillance is an evolving cultural phenomenon. Although the surveillance discourse often uses terminology that is associated with visual metaphors derived from historical societal experiences of state-based secret police, the dominant form of surveillance in the twenty first century is based on the collection and computation of data. Traditional metaphors of surveillance focus on the acts of watching and being watched. The state is conceived as a public eye surreptitiously watching both the public and private lives of citizens. Contemporary metaphors of surveillance focus more on mass collection of data points, creating vast stores of information which can be used to construct models of human behaviours, and an emphasis on empirical rather than visual terminology [2]. In contrast to traditional metaphors used to discuss surveillance, the contemporary discourse employs metaphors that are impersonal and formal. By focusing on technological concepts such as big data, metadata, and analytics, contemporary surveillance metaphors are reframing debates about privacy. Rather than discussing the boundaries of the state's presence in citizens' lives, contemporary metaphors draw attention to the pervasive technological capabilities of the state and a purported balance between security and liberty $[35,47]$.

One of the key arguments in debates about balancing security with liberty is the extent of the individual right to and expectation of privacy from observation by the state [37]. In this context, privacy can be framed as a general protection of the individual from unreasonable observation of behaviours in private spaces. In the twenty-first century the balance between the assumption of non-observable behaviour in private places, such as behind walls or in darkness, has been skewed by the pervasive collection of data by a range of actors, many of them non-state entities, including major transnational corporations. Online behaviours, activities, and identities have created a more complete digital personhood that allows the state to build more a complete picture of an individual this "virtual identity" has the potential to identify and expose an individual's private behaviours, attitudes, or beliefs [36, 80]. An exclusive focus on privacy for the sake of protecting individual privacy is reductionist, because privacy protections can be seen as safeguards for other aspects of citizen's lives, including restrictions on public expression and association, as well as protection from some forms of discrimination [9]. Information and data privacy can be seen as bulwarks against state encroachment into social and societal norms bounded and protected by contemporary liberal political values [70].

Information privacy is frequently conceived in terms of "fair information practices" which relate to communicative control ([49], 19). Communicative control is determined by the extent to which the subjects of data generation and collection know about and can influence how data about them are gathered, stored, analysed, shared, and used [49, 67]. This presumption of control extends beyond protecting personal details to include protection from institutional power. The power imbalance between surveillance apparatuses and the subjects of surveillance can be illustrated with three simple examples: blackmail, discrimination, persuasion [69]. The ability 
to exploit personal data to create social sorting categories has expanded significantly in the post-9/11 era $[44,90]$. Advancements in surveillance technologies have precepted an evolution of disciplinary societies into societies of control, empowering an omnipresent intelligence apparatus in relation to private citizens.

\section{Technological Evolution of the Surveillance State}

The contemporary national security state of the twentieth century was largely defined by great power struggles and deterrence. Throughout the post-Cold War period, the role of the state in providing security has undergone two significant changes. One change is the increased focus on internal threats to the security of the state under the banner of counterterrorism [68]. The other change is the impetus to monitor individuals at scale in order to detect indicators of threat behaviours [51]. This has intensified scrutiny of populations for the purpose of security, leading to the expansion of the surveillance functions of the state into an all-encompassing intelligence system capable of pervasive and invasive mass surveillance of foreign and domestic populations [78]. The evolution of the formal surveillance from a focus on homeland security to the modern intelligence state reflects the novel application of technology to security challenges and the coevolution of technology, data, and intelligence capability in the twenty-first century.

\subsection{The Security State}

Security politics in the post-9/11 period have been dominated by counterterrorism in much the same way that perpetual threat of nuclear annihilation defined the Cold War period. The security state of the twenty-first century has been largely preoccupied by containing threats from non-state actors at home and abroad. Internal security, an enduring priority for the state, has become a central policy debate around the world. The contemporary expansion of the concept of security now includes a range of individual, transnational, and non-state issues [18]. Alongside a broad "new security agenda" [16], encompassing a non-traditional security threats, there has been increasing focus on domestic threats under the banner of homeland security [62]. Conceptual confusion about security, including what is, how it attained, and what it represents $[6,13]$, initially clouded attempts to create holistic homeland security policies [83].

States initially gravitated towards risk reduction and proactive security intelligence and law enforcement policies in order to meet the most prevalent threats to public safety. This mirrored a more general trend in policing by risk that had been developing in community policing for decades [53, 57]. However, security is both an objective measure of risk and safety and also a subjective interpretation of risk in a given situation [73]. Despite rapid advancements in risk reduction, the security 
state quickly found itself lacking in managing risk perceptions. Public reactions to terrorist violence underscored the need to manage both risk reduction and public perceptions of safety. These converging impetuses led to widespread adoption of technological solutions to capability gaps in surveillance and intelligence.

Throughout the 2000s an increasingly capable and competent security state emerged. In some ways, the security state paralleled Ulrich Beck's [7] risk society. The overarching surveillance and intelligence apparatus of the security state served three main securitising functions in society. The first function was to restructure and repurpose institutions to include them in what would become the surveillance state. Burgeoning intelligence communities, intelligence fusion centres, and publicprivate data sharing arrangements [71] around the world suggest that the expansion of the security state has yet to reach its zenith. The second function was to build the capacity of the state to respond to domestic threats. Examples of the creation or enhancement of security intelligence, border protection, and law enforcement entities to bolster homeland security abound [62]. The third function was the subtle shift from policing the citizen actor within society to surveillance of the citizen threat to the state. Following the axiom that a person with nothing to hide has nothing to fear from surveillance [81], citizens have been effectively reframed as a potential source of threat to society. The security state thus paved the way for an expansionist surveillance state, justifying its penchant for panopticism under the guise of necessity.

\subsection{The Surveillance State}

The surveillance state emerged in the early twenty-first century alongside rapid advancements in ICT. New technologies have created a host of new opportunities and new vulnerabilities for intelligence collection and analysis, mostly related to the proliferation of big data. The surveillance implications of big data relate to both the unprecedented generation of data by individuals and a raft of new avenues for recording, accessing, and storing data [27, 36]. Major tech companies have benefited from nearly unilateral control over the capability to conduct pervasive data surveillance on individual consumers. This capability largely stems from mobile devices [43], but extends to a range of information services that major providers such as Amazon, Apple, and Google include in their product suites [54]. Governmental access to both the data and the collection platforms created by major tech companies and frequently used by consumers created a new conception of mass surveillance for the purposes of counterterrorism and homeland security [11].

From individual user profiles and search histories, to GPS location data and Bluetooth and Wi-Fi connections logs, to social media accounts and digital currency transactions, the sheer volume and speed of unique data generated by individuals engaging in their digital lives around the world is staggering [74]. The quantity, generation, and diversity of the data which governments collect, monitor, and analyse continue to increase rapidly. This is sometimes called the "five V's" of big data, which refers to the velocity, volume, value, variety, and veracity of data [29]. Access to these data 
and evolving methods of analysis has created a variety of new forms of information that did not previously exist, such as comprehensive archives of location data collected by mobile devices ([36], 144-149). Meanwhile, the capacity to mine data sources, to monitor data flows in real-time, and to construct comprehensive models of individuals and their behaviour is a controversial issue because it enables a degree of passive surveillance that was not possible only a few decades ago ([36], 183-266). Clarke [21] termed this capability "data surveillance" and defined it as the ability to use data and analytics to effectively observe and record an individual, object, or organisation.

The technical collection of vast repositories of data by mobile devices has afforded the security apparatus of the state an unprecedented ability to gather and analyse data in ways which enable mass surveillance [75]. Meanwhile, new forms of data have coevolved with information and communication technologies, creating new methods of analysis and new kinds of intelligence [52,65]. With the information collected through mass surveillance programs, intelligence analysts have become both better informed and burdened by the volume of data available to them. With expansive archives of digital information to sift through, the task of sorting, collating and categorising information has become more laborious [56]. The tasks involved in separating important details from trivial data and in deriving meaning from patterns and trends have become more intellectually challenging and increasingly resource intensive $[27,55]$. One way of alleviating the burden of data collection on the state has been through the implementation of open source and crowd sourced data to complement data surveillance [61], which brings additional actors into contact with the mechanisms of the surveillance state.

\subsection{The Intelligence State}

The intelligence state is an evolution of the surveillance state that uses cutting edge technological and analytical capabilities to erode the previous boundaries of surveillance. The rise of the intelligence state has been enabled by the data generated through persistent invasive surveillance and empowered by analytical techniques such as network analysis, general Pattern-of-Life (POL) analysis, and Activity-Based Intelligence (ABI). The application of computer assisted modelling and predicative analysis to behavioural data creates new opportunities for the intelligence state to incorporate a broad range of technology-supported capabilities to conduct behavioural analysis, geospatial intelligence, POL analysis, and ABI [10]. The starting point for these methods is mass data collection and behavioural analytics. In general, behavioural analysis is a process of assessing and modelling routines, patterns, and events in interpersonal, public, and online behaviours in data about individuals and groups $[48,59]$. Behavioural data can be enhanced with geospatial intelligence, which is derived from structured analysis of geographic, spatial, and imagery information [5, 38] and used to model physical, informational, and behavioural patterns. 
Simple patterns in complex data can be highly revealing ([36], pp. 6-12). POL analysis can model patterns of association between people, places, and objects to identify nodes, events, patterns, and outliers in relational data [33]. These patterns in individual routines can provide significant insight into personal information without directly accessing private data or employing overt surveillance methods. Examples abound in contemporary society. One such example is the use of shopping data to personalise online advertisements on web sites and social media platforms. Another example is the use of mass gathered location data to monitor, predict, and manipulate traffic flows. A third example is the use of multiple data sources and methods of analysis to create an "ensemble effect," which can illuminate personal preferences, behaviours, and patterns despite the limitations of any of the individual sources used [76]. Ensemble effects are sometimes used with crowd sourced and mass collected intelligence because they offer deeper and multifaceted insight into patterns and trends through data modelling [14].

$\mathrm{ABI}$ is a method of data modelling which focuses on actions and activities, incorporating contextual, biographical, and relational data which can be used to discover and systematise patterns and trends in a subject's behaviours [22, 46]. ABI and similar predictive analytical methods empower the intelligence state to create models of subjects or targets of investigations, operations, and defensive countermeasures [10]. Intelligence models can be used for five basic purposes across the military, national security and law enforcement domains: description, collaboration, explanation, exploration and prediction [86]. Description is a method used to represent known details of an event, situation, or process. Collaboration allows teams of individuals to create a common representation of the modelled subject and then manipulate, update, and modify the shared model collectively. Explanation involves generating and testing hypotheses that potentially explain relationships between entity, event, or process data. Exploration is used to evaluate changes in the structure and dynamics of modelled subjects, explore causal influences between data, and anticipate behaviours. Prediction can be used to estimate likely events, to optimise processes and actions, and to pursue circumstances that are generally consistent with preferable outcomes $[8,86]$.

Activity-Based models have provided the intelligence state with new avenues for proactive and preventative actions to reduce risks, control crime, and identify individuals who display markers of targeted behaviours. For example, predictive policing models have enabled law enforcement agencies to increase resource allocation to locations and crime types deemed high risk, to develop intervention programs for specific crime types, and to identify functional, situational, and geographical factors for risks to safety and security [66]. Similarly, POL and ABI analyses have enabled intelligence and security bureaucracies to build models of adversary behavioural patterns and Modus Operandi, identify critical security events in progress, and enhance situational awareness [4]. These approaches to intelligence analysis require the data generated by the surveillance state as a fundamental input. However, the insight into the personal and private exceeds the boundaries that commonly exist 
on physical, technical, and digital surveillance methods. For example, pattern detection algorithms used in threat behaviour models designed to support counterterrorism can bring individuals who have not been identified by the authorities under scrutiny. Where previously a warrant might have been needed to search a suspect's home or telephone records, their digital identity can be rapidly mined without facing traditional physical or temporal obstacles to surveillance.

\section{The Dividual and the Intelligence State}

The technological supremacy of the modern intelligence state over the individual citizen has the potential to reduce personhood to a sum of data points. Deleuze ([24], 5) coined the term 'dividual' to explain how a society of control could devolve the irreducible and autonomous agency of the individual to categories and classes with or without access. The dividual can also be conceived as a reducible unit of analysis, regarded by the intelligence state as combination of behavioural, biometric, communication, identity, location, and transaction data. The capability to exert control over society through moderating access to information, systems, and agency has grown immeasurably in the twenty first century. This raises two concerns for the evolving relationship between society and the intelligence state. The first concern is the emergent sense of self that is becoming more transparent both in public and private spaces. The second concern is the continuation of this trajectory in tandem with emerging technologies of control. The implications of these looming issues include the potential for a near-omniscient society of control and the gradual shaping of both civil society and citizenry into idealised state-designated models of behaviour and thought.

\subsection{The Transparent Self}

Contemporary societies are routinely subjected to levels and forms of surveillance which were not possible only a decade ago. The kinds of technologies that have been engrained in the daily routine of many people have also captured a detailed record about those routines ([69], 1936). For some, the persistence of surveillance technologies has been embraced as either a mixed blessing, permitting formerly unattainable levels of efficiency and security, or an acceptable cost for access to digital services ([49], 19). Certain forms of surveillance have been popularised in cinema and media [63], and have been accepted as a part of digital life in some societies. The kinds of surveillance technologies that people are increasingly conscious of in their everyday lives include communication metadata, GPS location data, social media feeds, and shopping activity. The kinds of surveillance that are less widely appreciated are user analytics applied to reading habits, browsing behaviours, and search term data [69]. 
These technologies have created a transparent self, one which is rendered more visible and less protected from external scrutiny through ubiquitous surveillance and data collection technologies [41]. Technology compromises the self in three distinct ways. The first form of compromise is the removal or reduction of boundaries, such as clothing and the human body itself, which is rendered transparent by non-invasive surveillance equipment such as millimetre wave, $\mathrm{X}$-ray, and metal detecting scanners. The second form of compromise is the transparency of spaces formerly assumed to be non-observable, such as private spaces behind doors and walls or concealed by darkness, which are visible with electro-optical and remote audio sensing technologies. The third form of compromise is the burring distinction between thoughts and actions which are deemed to pose a threat to the security of the state. The methods used to render internal thoughts observable are commonplace in the kinds of behavioural analytics used by commercial entities [1, 42]. Similar technologies are problematic for states where the line between criminal actions and thoughts about criminality is being eroded. One example of this in the counterterrorism domain is the state's focus on Countering Violent Extremism (CVE) by monitoring and intervening in ideological debates involving extremist content [31]. The distinction between having undesirable but legal thoughts and committing illegal behaviours is often blurred in the language used in CVE and counterterrorism policies [34, 89].

Gradual acceptance of the transparent self lends itself to the potential for a similarly gradual formation of a transparent society [12]. Such a society, defined by the transparency of its citizens and the degree of state control over access to networks, is a significant step closer to Deleuze's [24] society of control. The transparent society lays the foundation for the further encroachment of data generating technology into the personal lives and personal spaces of citizens. An example of this is the Social Credit Score [40] system used by the People's Republic of China (PRC) to incentivise and deter specific private behaviours in accordance with its preferences for citizen behaviour [45]. Since the introduction of the Social Credit Score system in 2007, the PRC has been able to rank, categorise, and sort its citizens, allocating resources and privileges to those who conform and denying access to those who do not [20]. This illustrates the extant and potential capability of the intelligence state to use surveillance, data and algorithms to exercise control over society [26].

\subsection{Emerging Technologies of Control}

The rapid expansion of technological solutions to security challenges in the post-9/11 era led to widespread public debate over the role of data surveillance in responding to the threat of domestic and transnational terrorism to the internal security of the state. During the 2000s, it was not feasible to use predictive analytics to effectively counter the threat of terrorism. The likelihood of errors, including both false positives and false negatives, was high due to limited data on the small-scale patterns of threat actor behaviour and the nascent capability of the security state to collect, store, 
and analyse data [39]. This line of argument, which originated in the brief presmartphone period at the beginning of the twenty-first century, accurately reflected the limits of data availability, technical means of collection, analytical methods, and security intelligence models at the time. Much has changed since. While intelligence practitioners debate the relative effectiveness of emerging and enduring surveillance technologies $[19,50]$ there is little doubt that the ability of the intelligence state to leverage data analytics has improved dramatically [58, 64].

Although critics may contend that, in the words of William Burroughs [15], "control can never be a means to any practical end", the modern intelligence state has created a system of control that serves as a means to greater levels of compliance and security than even societies of discipline could muster. The implications of nearcertain future developments into surveillance and analytical technologies warrant further consideration. The implications of pattern analysis for the extension of control include the potential to create pervasive social monitoring and social sorting systems [49]. These systems would enhance the disciplinary power of predictive algorithms by enabling control over access to social benefits, information, knowledge systems, and opportunities [23]. A complex of disciplinary and control systems would be further empowered by progression in POL, ABI, and behavioural analytics [22]. Each of these technological advancements could permit further intrusion into the private and personal if not kept in check through robust protective measures. As such, the surveillance technologies currently under development by the intelligence state constitute technologies of control.

\section{Conclusions}

The rise of the modern intelligence state was, ostensibly, a technologically driven facet of the counterterrorism policies adopted by many countries in the post-9/11 era. Debates about the balance to be struck between privacy and security have largely focused on surveillance while the technical capability of the state evolved from a focus on surveillance to embracing intelligence and analytical modelling. Mirroring the conceptual evolution of disciplinary societies towards societies of control, the modern intelligence state has garnered an expansive reach into the previously personal and private spaces of citizens. This reach has been enabled by three emergent features of the modern intelligence state: persistent data surveillance, pattern-of-life analysis, and activity-based intelligence. Intelligence models provide insight into patterns of human behaviour and outlier activities which do not fit standard patterns. The dehumanising of data parallels a concomitant deindividualising of citizens, who may be controlled through mechanisms of social sorting. The nascent capacity to exercise influence by incentivising and deter specific behaviours is eroding the previous limits on the surveillance state. By monitoring and categorising citizen behaviours, the intelligence state does not just know the personal and private, it can to some extent shape what the private may be or think. With robust oversight, 
these technologies may be beneficial to security in many ways. Nevertheless, the potential to redefine ethical boundaries requires strict attention.

\section{References}

1. Abbot D (2014) Applied predictive analytics: principles and techniques for the professional data analyst. John Wiley \& Sons, Hoboken, NJ

2. Agre PE (1994) Surveillance and capture: two models of privacy. Inf Soc 10(2):101-127

3. Andrejevic M (2012) Ubiquitous surveillance. In: Ball K, Haggerty KD, Lyon D (eds) Routledge handbook of surveillance studies. Routledge, London and New York, pp 91-98

4. Antony RT (2016) Data fusion support to activity-based intelligence. Artech House, Norwood, MA

5. Bacastow TS, Bellafiore D (2009) Redefining geospatial intelligence. Am Intell J 27(1):38-40

6. Baldwin DA (1997) The concept of security. Rev Int Stud 23(1):5-26

7. Beck U (1992) Risk society: towards a new modernity. Sage, London

8. Moses LB, Chan J (2018) Algorithmic prediction in policing: assumptions, evaluation, and accountability. Policing Soc 28(7):806-822

9. Bernal P (2016) Data gathering, surveillance and human rights: recasting the debate. J Cyber Policy 1(2):243-264

10. Biltgen P, Ryan S (2016) Activity-based intelligence: principles and applications. Artech House, Norwood, MA

11. Brayne S (2017) Big data surveillance: the case of policing. Am Sociol Rev 82(5):977-1008

12. Brin D (1999) The transparent society: will technology force us to choose between privacy and freedom? Basic Books, New York

13. Brooks DJ (2010) What is security: definition through knowledge categorization. Secur J 23(3):225-239

14. Bulger NJ (2016) The evolving role of intelligence: migrating from traditional competitive intelligence to integrated intelligence. Int J Intell Secur Publ Affairs 18(1):57-84

15. Burroughs WS (1959) The naked lunch. Olympia Press, Paris

16. Buzan B, Wæver O, de Wilde J (1998) Security: a new framework for analysis. Lynne Rienner, Boulder, $\mathrm{CO}$

17. Byman D (2014) The intelligence war on terrorism. Intell National Secur 29(6):837-863

18. Caldwell D, Williams RE (2011) Seeking security in an insecure world. Rowman and Littlefield, Lanham, MA

19. Cayford M, Pieters W (2018) The effectiveness of surveillance technology: what intelligence officials are saying. Inf Soc 34(2):88-103

20. Chen Y, Cheung AS (2017) The transparent self under big data profiling: privacy and Chinese legislation on the social credit system. Am J Comp Law 12(2):356-377

21. Clarke R (1994) The digital persona and its application to data surveillance. Inf Soc 10(2):77-92

22. Craddock R, Watson D, Saunders W (2016) Generic pattern of life and behaviour analysis. In: 2016 IEEE international multi-disciplinary conference on cognitive methods in situation awareness and decision support (CogSIMA), San Diego, 21-25 March 2016

23. de Laat PB (2019) The disciplinary power of predictive algorithms: a Foucauldian perspective. Ethics Inf Technol 21(4):319-329

24. Deleuze G (1992) Postscript on the societies of control. October 59:3-7

25. Elmer G (2012) Panopticon-discipline-control. In: Ball K, Haggerty KD, Lyon D (eds) Routledge handbook of surveillance studies. Routledge, London and New York, pp 21-29

26. Erwin S (2015) Living by algorithm: smart surveillance and the society of control. Humanities Technol Rev 34:28-69

27. Ferguson AG (2017) The rise of big data policing: surveillance, race, and the future of law enforcement. New York University Press, New York 
28. Foucault M (1995) Discipline and punish: the birth of the prison. Random House, New York

29. Gandomi A, Haider M (2015) Beyond the hype: big data concepts, methods, and analytics. Int J Inf Manage 35(2):137-144

30. Gandy O (1993) The panoptic sort: a political economy of personal information. Westview, Boulder CO

31. Gielen A-J (2019) Countering violent extremism: a realist review for assessing what works, for whom, in what circumstances, and how? Terrorism Political Violence 31(6):1149-1167

32. Haggerty K, Ericson R (2000) The surveillant assemblage. Br J Sociol 54(1):605-622

33. Hardy J, Lushenko P (2012) The high value of targeting: a conceptual model for using HVT against a networked enemy. Def Stud 12(3):413-433

34. Harris-Hogan S, Barrelle K, Zammit A (2016) What is countering violent extremism? Exploring CVE policy and practice in Australia. Behav Sci Terrorism Political Aggression 8(1):6-24

35. Hayden MV (2014) Balancing security and liberty: the challenge of sharing foreign signals intelligence. Notre Dame J Law, Ethics Publ Policy 19(1):247-260

36. Henschke A (2017) Ethics in an age of surveillance: personal information and virtual identities. Cambridge University Press, Cambridge

37. Henschke A (2020) Privacy, the internet of things and state surveillance: handling personal information within an inhuman system. Moral Philosophy Politics 7(1):123-149

38. Herchenrader T, Myhill-Jones S (2015) GIS supporting intelligence-led policing. Police Pract Res 16(2):136-147

39. Jonas J, Harper J (2006) Effective counterterrorism and the limited role of predictive data mining. CATO Institute, Washington, DC

40. Kobie N (2019) The complicated truth about China's social credit system. Wired 7 June

41. Lanzing M (2016) The transparent self. Ethics Inf Technol 18(1):9-16

42. Larose DT, Larose CD (2015) Data mining and predictive analytics. John Wiley \& Sons, Hoboken, NJ

43. Laurila JK, Gatica-Perez D, Aad I, Blom J, Bornet O, Do T-M-T, Dousse O, Eberle J, Miettinen M (2012) The mobile data challenge: big data for mobile computing research. In: Pervasive computing, Newcastle

44. Levi M, Wall DS (2004) Technologies, security, and privacy in the post-9/11 European information society. J Law Soc 31(2):194-220

45. Liang F, Das V, Kostyuk N, Hussain MM (2018) Constructing a data-driven society: china's social credit system as a state surveillance infrastructure. Policy Internet 10(4):415-453

46. Long LA (2013) Activity based intelligence: understanding the unknown. Intelligencier 20(2):7-16

47. Lowe D (2016) Surveillance and international terrorism intelligence exchange: balancing the interests of national security and individual liberty. Terrorism Political Violence 28(4):653-673

48. Lyon D (2002) Everyday surveillance: personal data and social classifications. Inf Commun Soc 5(2):242-257

49. Lyon D (2003a) Surveillance as social sorting: computer codes and mobile bodies. In: Lyon D (ed) Surveillance as social sorting: privacy, risk, and digital discrimination, Routeledge, London and New York, pp 13-30

50. Lyon D (2003b) Surveillance technology and surveillance society. In: Misa TJ, Brey P, Feenberg A (eds) Modernity and technology, The MIT Press, Cambridge, MA, pp 161-183

51. Lyon D (2014) Surveillance, snowden, and big data: capacities, consequences, critique. Big Data Soc 1(2):2053951714541861

52. Maguire M (2009) The birth of biometric security. Anthropol Today 25(2):9-14

53. Maguire M (2000) Policing by risks and targets: some dimensions and implications of intelligence-led crime control. Polic Soc 9(4):315-336

54. Mayer-Schönberger V, Ramge T (2018) A big choice for big tech: share data or suffer the consequences. Foreign Aff 97:48-54

55. McCue C (2015) Data mining and predictive analysis: intelligence gathering and crime analysis. Butterworth-Heinemann, Oxford 
56. McCue C, Parker A (2003) Connecting the dots: data mining and predictive analytics in law enforcement and intelligence analysis. Police Chief 70(10):115-122

57. McGarrell EF, Freilich JD, Chermak S (2007) Intelligence-led policing as a framework for responding to terrorism. J Contemp Crim Justice 23(2):142-158

58. Meijer A, Wessels M (2019) Predictive policing: review of benefits and drawbacks. Int J Publ Adm 42(12):1031-1039

59. Mena J (2011) Machine learning forensics for law enforcement, security, and intelligence. CRC Press, Boca Raton

60. Miller J-A, Miller R (1987) Jeremy Bentham's panoptic device. October 41:3-29

61. Monahan T, Mokos JT (2013) Crowdsourcing Urban surveillance: the development of homeland security markets for environmental sensor networks. Geoforum 49:279-288

62. Mueller J, Stewart MG (2011) Terror, security, and money: balancing the risks, benefits, and costs of homeland security. Oxford University Press

63. Muir L (2012) Control space?: cinematic representations of surveillance space between discipline and control. Urban Surveillance 9(3):263-279

64. Nunn S (2001) Police technology in cities: changes and challenges. Technol Soc 23:11-27

65. Pell SK, Soghoian C (2014) Your secret stingray's no secret anymore: the vanishing government monopoly over cell phone surveillance and its impact on national security and consumer privacy. Harvard J Law Technol 28(1):2-75

66. Perry WL, McInnis B, Price CC, Smith S, Hollywood JS (2013) Predictive policing: forecasting crime for law enforcement. RAND Corporation, Santa Monica, CA

67. Pieters W (2011) The (social) construction of information security. Inf Soc 27(5):326-335

68. Richards J (2012) Intelligence dilemma? Contemporary counter-terrorism in a liberal democracy. Intell National Secur 27(5):761-780

69. Richards NM (2013) The dangers of surveillance. Harv Law Rev 126(7):1934-1965

70. Robbins S, Henschke A (2017) Designing for democracy: bulk data and authoritarianism. Surveillance Soc 15(3):582-589

71. Russel RL (2007) Achieving all-source fusion in the intelligence community. In: Johnson LK (ed) Handbook of intelligence studies. Routledge, London and New York, pp 189-198

72. Schneier B (2003) Beyond fear: thinking sensibly about security in an uncertain world. Copernicus Books, New York

73. Schneier B (2009) Schneier on security. Wiley Blackwell, Indianapolis

74. Schneier B (2015) Data and goliath: the hidden battles to collect your data and control your world. W. W. Norton, New York

75. Schuster S, van den Berg M, Larrucea X, Slewe T, Ide-Kostic P (2017) Mass surveillance and technological policy options: improving security of private communications. Comput Standard Interfaces 50:76-82

76. Siegel E (2013) Predictive analytics: the power to predict who will click, buy, lie, or die. John Wiley \& Sons, Hoboken, NJ

77. Sims J (2007) Intelligence to counter terror: the importance of all-source fusion. Intell National Secur 22(1):38-56

78. Slobogin C (2013) Panvasive surveillance, political process theory, and the non-delegation doctrine. Georgetown Law Rev 102:1721-1776

79. Slobogin C (2013) Rehnquist and panvasive searches. Mississippi Law J 82(2):307-328

80. Solove DJ (2004) The digital person: technology and privacy in the information age. New York University Press, New York

81. Solove DJ (2011) Nothing to hide: the false trade-off between privacy and security. Yale University Press, New Haven and London

82. Steadman P (2007) The contradictions of Jeremy Bentham's panopticon penitentiary. J Bentham Stud 9:1-31

83. Stolberg AG (2010) Making national security policy in the 21st century. In: Bartholomees JB (ed) The U.S. army war college guide to national security issues, Strategic Studies Institute, Carlisle, PA, pp 29-45 
84. Svendsen A (2008) The globalization of intelligence since 9/11: frameworks and operational parameters. Camb Rev Int Aff 21(1):129-144

85. Tuinier P (2021) Explaining the depth and breadth of international intelligence cooperation: towards a comprehensive understanding. Intell National Secur 36(1):116-138

86. Waltz E (2014) Quantitative intelligence analysis, applied analytic models, simulations, and games. Rowman and Littlefield, Lanham, MA

87. Watt E (2017) The right to privacy and the future of mass surveillance. Int J Human Rights 21(7):773-799

88. Weller T (2012) The information state: an historical perspective. In: Ball K, Haggerty KD, Lyon D (eds) Routledge handbook of surveillance studies. Routledge, London and New York, pp 57-63

89. Williams MJ, Horgan JG, Evans WP (2016) The critical role of friends in networks for countering violent extremism: toward a theory of vicarious help-seeking. Behav Sci Terrorism Political Aggression 8(1):45-65

90. Zappalà G (2015) Killing by metadata: Europe and the surveillance-targeted killing nexus. Global Affairs 1(3):251-258

John Hardy is Assistant Dean of Graduate Studies at Rabdan Academy. John was previously Director of Security Studies at Macquarie University and a Research Fellow at the Australian National Security College (ANU). He has extensive experience in delivering academic and professional development training around the world, specialising in national security, intelligence, counterterrorism, and law enforcement. His current research projects focus on practical national security policy issues, such as the application of narrative analysis to extremist propaganda, mechanisms of coercive power in unequal political contests, and the use of emerging technologies to enhance security intelligence operations.

Open Access This chapter is licensed under the terms of the Creative Commons Attribution 4.0 International License (http://creativecommons.org/licenses/by/4.0/), which permits use, sharing, adaptation, distribution and reproduction in any medium or format, as long as you give appropriate credit to the original author(s) and the source, provide a link to the Creative Commons license and indicate if changes were made.

The images or other third party material in this chapter are included in the chapter's Creative Commons license, unless indicated otherwise in a credit line to the material. If material is not included in the chapter's Creative Commons license and your intended use is not permitted by statutory regulation or exceeds the permitted use, you will need to obtain permission directly from the copyright holder.

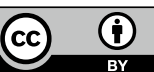

